\title{
Phase I ficlatuzumab monotherapy or with erlotinib for refractory advanced solid tumours and multiple myeloma
}

\begin{abstract}
A Patnaik ${ }^{*}, 1$, G J Weiss ${ }^{2,6}$, K P Papadopoulos ${ }^{1}$, C C Hofmeister ${ }^{3}$, R Tibes $^{2,7}$, A Tolcher $^{1}$, R Isaacs ${ }^{4,8}, \mathrm{~J} \mathrm{Jac}^{5}$, M Han ${ }^{5,9}$, F C Payumo ${ }^{5}, M^{2}$ M Cotreau ${ }^{5,10}$ and R K Ramanathan ${ }^{2}$

${ }^{1}$ Clinical Research, South Texas Accelerated Research Therapeutics (START), 4383 Medical Drive, San Antonio, TX 78229, USA; ${ }^{2}$ Division of Hematology and Medical Oncology, Virginia G Piper Cancer Center, 10460 North 92nd Street, Suite 101, Scottsdale, AZ 85258, USA; ${ }^{3}$ Hematology Division Internal Medicine Department, Ohio State University, 320 West 10th Avenue, Columbus, OH 43210, USA; ${ }^{4}$ Merck, 2000 Galloping Hill Road, Kenilworth, NJ 07033, USA and ${ }^{5}$ AVEO Pharmaceuticals, Inc., 75 Sidney Street, Cambridge, MA 02139, USA
\end{abstract}

Background: Ficlatuzumab, a humanised hepatocyte growth factor (HGF) IgG1 $\kappa$ inhibitory monoclonal antibody, was evaluated for recommended phase II dose (RP2D), safety, pharmacokinetics (PKs), antidrug antibody (ADA), pharmacodynamics (PDs) and antitumour activity as monotherapy or combined with erlotinib.

Methods: Patients with solid tumours received ficlatuzumab 2, 5, 10 or $20 \mathrm{mg} \mathrm{kg}^{-1}$ intravenously every 2 weeks (q2w). Additional patients were treated at the RP2D erlotinib.

Results: Forty-one patients enrolled at doses $\leqslant 20 \mathrm{mg} \mathrm{kg}^{-1}$. Common adverse events (AEs) included peripheral oedema, fatigue and nausea. Three patients experienced grade $\geqslant 3$ treatment-related hyperkalaemia/hypokalaemia, diarrhoea or fatigue. Best overall response (44\%) was stable disease (SD); median duration was 5.5 months (0.4-18.7 months). One patient has been on therapy with SD for $>4$ years. Pharmacokinetics of ficlatuzumab showed low clearance $\left(0.17-0.26 \mathrm{ml} \mathrm{h}^{-1} \mathrm{~kg}^{-1}\right)$, a half-life of $6.8-9.4$ days and dose-proportional exposure. Ficlatuzumab/erlotinib had no impact on the PK of either agent. No ADAs were detected. Ficlatuzumab increased serum HGF levels.

Conclusions: Recommended phase II dose is $20 \mathrm{mg} \mathrm{kg}^{-1} \mathrm{q} 2 \mathrm{w}$ for ficlatuzumab monotherapy or with erlotinib. Preliminary antitumour activity and manageable AEs were observed. Pharmacokinetics were dose-proportional and consistent with other lgG therapeutics. Ficlatuzumab was not immunogenic, and serum HGF was a potential PD marker.

Hepatocyte growth factor (HGF) is the only known ligand for the c-Met receptor tyrosine kinase (Bottaro et al, 1991; Weidner et al, 1993; Zhang et al, 2010; Yap et al, 2011). Hepatocyte growth factor stimulation of c-Met results in activation of key oncogenic signalling pathways that increase cell proliferation, survival, migration and invasion (Birchmeier et al, 2003). Hepatocyte growth factor-mediated autocrine and paracrine activation loops are found in a number of human cancers, including breast, lung, bladder, gastric, head and neck, and brain cancers, as well as multiple myeloma (Christensen et al, 2005; Gherardi et al, 2012).

\footnotetext{
*Correspondence: Dr A Patnaik; E-mail: amita.patnaik@start.stoh.com

${ }^{6}$ Current address: Cancer Treatment Centers of America, 14200 Celebrate Life Way, Goodyear, AZ 85338, USA

${ }^{7}$ Current address: Mayo Clinic Cancer Center, 13400 East Shea Boulevard, Scottsdale, AZ 85259, USA.

${ }^{8}$ Current address: Novartis Pharmaceuticals Corporation, 1 Health Plaza, East Hanover, NJ 07936, USA.

${ }^{9}$ Current address: Novartis Institutes for Biomedical Research, 250 Massachusetts Avenue, Cambridge, MA 02139, USA.

${ }^{10}$ Current address: Alnylam Pharmaceuticals, 300 Third Street, Cambridge, MA 02142, USA.
}

Received 13 January 2014; revised 25 April 2014; accepted 7 May 2014; published online 5 June 2014 
Further, HGF expression is a predictor of poor prognosis (Trusolino and Comoglio, 2002; Birchmeier et al, 2003; Betsunoh et al, 2007; Drebber et al, 2008; Sasaki et al, 2008; Ponzo et al, 2009; Pour et al, 2010; Gherardi et al, 2012).

Targeting both HGF/c-Met and epidermal growth factor receptor (EGFR) signalling pathways may be an effective antitumour strategy (Guo et al, 2008). In studies of breast, squamous cell carcinoma of head and neck, pancreatic, and non-small cell lung cancer (NSCLC) cancer models, tumour growth was synergistically inhibited by $\mathrm{HGF} / \mathrm{c}-\mathrm{Met}$ pathway inhibitors in combination with EGFR inhibitors (Tang et al, 2008; Seiwert et al, 2009; Zhang et al, 2010; Xu et al, 2011). c-Met amplification promotes resistance to the EGFR tyrosine kinase inhibitors erlotinib and gefitinib in NSCLC tumours with EGFR-activating mutations (Bean et al, 2007; Engelman et al, 2007). The clinical activity of combining $\mathrm{HGF} / \mathrm{c}-\mathrm{Met}$ pathway inhibitors onartuzumab with erlotinib was demonstrated in a randomised phase II NSCLC trial in patients with high c-Met levels. Therefore, evaluation of HGF/c-Met and EGFR inhibitors is warranted.

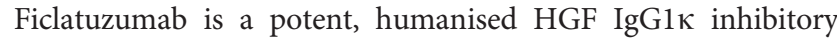
monoclonal antibody that neutralises HGF/c-Met binding, thus inhibiting HGF-induced c-Met phosphorylation, cell proliferation, cell invasion and cell migration (Birchmeier et al, 2003). Ficlatuzumab inhibits growth of HGF/c-Met-dependent tumours in autocrine or paracrine pre-clinical xenograft models, such as glioblastoma (GBM) (Meetze et al, 2009a), NSCLC (Meetze et al, 2009b) and pancreatic cancer (Meetze et al, 2009c), making it a candidate for the treatment of multiple cancer types (Patnaik et al, 2010; Tan et al, 2011). Ficlatuzumab demonstrated synergistic activity in combination with the EGFR pathway inhibitors erlotinib and cetuximab and achieved nearly complete tumour regression with cetuximab in a paracrine NSCLC xenograft model (Meetze et al, 2009c). Ficlatuzumab also demonstrated additive antitumour activity when combined with chemotherapy in GBM intracranial models (Meetze et al, 2009a).

This first-in-human phase I study of ficlatuzumab evaluated doses from 2 to $20 \mathrm{mg} \mathrm{kg}^{-1}$ as monotherapy in patients with advanced solid tumours or multiple myeloma, and in combination with erlotinib in patients with advanced solid tumours (NCT00725634).

\section{PATIENTS AND METHODS}

Study design. This study was performed in accordance with the principles outlined in the Declaration of Helsinki. The primary study objectives were to determine the safety, tolerability, doselimiting toxicities (DLTs) and recommended phase II dose (RP2D) of ficlatuzumab as monotherapy in patients with relapsed or refractory solid tumours, lymphoma or multiple myeloma, and in combination with erlotinib in patients with relapsed or refractory solid tumours. Secondary objectives included characterisation of the pharmacokinetic (PK) profiles of ficlatuzumab with and without erlotinib; evaluation of preliminary antitumour activity; and evaluation of the effects of ficlatuzumab on exploratory biomarkers in blood and bone marrow (BM).

Patients. All patients were aged $\geqslant 18$ years and signed an institutional review board-approved consent form before starting the clinical trial. Eligible patients had advanced refractory solid tumour malignancies. Patients with multiple myeloma must have satisfied standard published requirements (Durie et al, 2006). Enrolment criteria for all cohorts are provided in Supplementary Appendix Table A1 (online only). Pertinent eligibility included written informed consent before study entry, Eastern Cooperative Oncology Group performance status of 0 or 1, and no radiotherapy within 3 weeks before the first study drug infusion. All patients were required to have adequate blood, kidney and liver laboratory parameters. Other than patients with GBM, who could enrol in the safety expansion cohort or in the erlotinib combination cohort, patients with central nervous system disease were excluded.

Patients with grade $\geqslant 2$ diarrhoea at baseline, inflammatory bowel disease, or acute onset of new or progressive pulmonary symptoms within 4 weeks before first study treatment were not eligible for the erlotinib combination cohort.

Escalating doses of intravenous (IV) ficlatuzumab at 2, 5, 10 or $20 \mathrm{mg} \mathrm{kg}^{-1}$ over $60 \mathrm{~min}$ once per 14-day cycle were administered in $3+3$ design (Storer, 1989). Dose-limiting toxicities were defined as any of the following drug-related toxicities occurring during the first two cycles of treatment: toxicity that resulted in dose reduction or interruption of treatment for $>2$ weeks; pertinent grade 3 haematologic or nonhaematologic toxicity; grade 3 neutropaenia lasting $\geqslant 5$ days; grade 4 thrombocytopenia associated with bleeding; and grade 4 haematologic or nonhaematologic toxicity of any duration.

Up to 12 additional patients per arm could subsequently be enrolled to receive ficlatuzumab at the RP2D in the safety expansion cohort (patients with solid tumours) or the multiple myeloma cohort $(n=4$, methods described in Supplementary Appendix Tables A2 and A3).

Patients in the erlotinib combination cohort were administered ficlatuzumab at the RP2D plus erlotinib $150 \mathrm{mg} \mathrm{day}^{-1}$ on day 1 of each cycle. No dose escalation was planned, but the dose of ficlatuzumab and/or erlotinib could be decreased stepwise. Doselimiting toxicities for the combination excluded grade 3 rash lasting $\leqslant 48 \mathrm{~h}$. A summary of cohort design and observed DLTs is provided in Supplementary Appendix Table A4.

Drug administration. The required dose of ficlatuzumab was admixed with $0.9 \%$ normal saline for a final concentration of 1.0 to $10.0 \mathrm{mg} \mathrm{ml}^{-1}$ given by IV administration over $60 \mathrm{~min}$. Pre-medication for nausea/vomiting or hypersensitivity reactions was permitted following any observed reactions after the first dose.

Safety evaluations. Patients were seen weekly during the first two cycles for a physical examination and routine laboratory tests and at the start of each subsequent cycle. Adverse events (AEs) were graded for severity according to National Cancer Institute Common Terminology Criteria for Adverse Events (version 3.0; Bethesda, MD, USA). Patients who received at least one treatment dose of ficlatuzumab were evaluable for safety analyses.

Efficacy evaluations. Patients had radiologic scans at baseline and every four cycles ( 8 weeks) for response assessments. After 1 year, scans were performed every six cycles (12 weeks). The guidelines of the Response Evaluation Criteria in Solid Tumors, version 1.0 (Brussels, Belgium) were used to assess efficacy in patients with solid tumours. For multiple myeloma patients, response was assessed according to the International Myeloma Working Group uniform response criteria (Durie et al, 2006). Efficacy parameters included objective response rate (complete response $(\mathrm{CR})+$ partial response $(\mathrm{PR})$ ), duration of response, duration of stable disease (SD) and time to progression. All subjects who completed 8 weeks of treatment (i.e., four or more cycles) with a disease assessment were evaluable for response.

Pharmacokinetic evaluations. Patients who received at least one dose of ficlatuzumab or erlotinib and had at least one measurable post-dose concentration were considered evaluable for PK analyses. Samples for PK analysis of ficlatuzumab and/or erlotinib were collected pre-dose, immediately after infusion, and at 1, 3, 6, $8,24,48$ and $72 \mathrm{~h}$ and 1-week post-dose in cycle 1; pre-dose, immediately after infusion, and at $2 \mathrm{~h}$ and 1-week post-dose in cycle 2; pre-dose and immediately after infusion in cycle 3 ; at 1 to 2 weeks post-dose in cycle 4; and pre-dose for each subsequent cycle through cycle 52 (details in the Supplementary Material). 
Serum ficlatuzumab levels were quantified by a validated enzyme-linked immunosorbent assay (ELISA) (PPD, Richmond, VA, USA). Ficlatuzumab was captured from serum by recombinant human HGF (R\&D Systems, Minneapolis, MN, USA) bound to a microtiter plate. Captured ficlatuzumab was then detected with polyclonal rabbit anti-human IgG-horseradish peroxidase (Dako Cytomation, Glostrup, Denmark). The range of detection was 2 to $150 \mu \mathrm{g} \mathrm{ml}^{-1}$. Assay accuracy and precision were $<20 \%$ as expressed by intraday and interday percentage error.

Plasma erlotinib levels were quantified by a validated, highperformance liquid chromatography with tandem mass spectrometry (MS-MS) assay (PPD). Plasma erlotinib was extracted with $50 \%$ acetonitrile containing internal standard (erlotinb-d6) followed by centrifugation. The supernatant was further diluted with $50 \%$ acetonitrile and analysed by liquid chromatography/MS-MS (Applied Biosystems, Grand Island, NY, USA). The range detection of the assay was between 10 and $10000 \mathrm{ng} \mathrm{ml}^{-1}$. Assay accuracy and precision were $<15 \%$ as expressed by intraday and interday percentage error.

Pharmacokinetic parameters were calculated by noncompartmental analysis using Phoenix WinNonLin, version 6.2 (Pharsight Corporation, Mountain View, CA, USA).

Ficlatuzumab antidrug antibody (ADA) analyses. Serum samples were collected before and after ficlatuzumab dosing at screen or pre-dose cycle 1 day 1 (C1D1), pre-dose C3D1 and subsequent odd cycles, as well as at 1-month follow-up. Antidrug antibody was detected using a pair of biotinylated and SULFO-TAG labelled (Mesoscale Discovery, Rockville, MD, USA) ficlatuzumab in a bridging electrochemiluminescence (ECL) method (detail provided in Supplementary Material).

Biomarker analyses. Serum samples were collected before and after ficlatuzumab dosing ranging from $2 \mathrm{~h}$ to 50 days after dose (Supplementary Table A5). Serum HGF levels were measured using an ELISA detection kit (R\&D Systems) as per the manufacturer's instruction and validated by PPD. Serum c-Met concentrations were determined by ECL detection using an anti-cMet polyclonal antibody targeting the extracellular domain labelled with biotin and SULFO-TAG (Mesoscale Discovery; experiment details are provided in Supplementary Material).

Twenty-nine of the 37 solid tumour patients enrolled (monotherapy or erlotinib combination) provided archival tissues for biomarker analysis using immunohistochemistry (IHC) for HGF and c-Met. As no paired samples from pre- and post-ficlatuzumab treatment were available, HGF pathway modulation by ficlatuzumab treatment was not evaluated.

Bone marrow aspirates were collected from the four subjects with multiple myeloma before and 2 to 3 days after treatment. Bone marrow cell pellet was collected and lysed in lysis buffer. Hepatocyte growth factor was measured by ELISA (R\&D Systems), whereas c-Met and p-Met were measured by multiplex ELISA using ECL detection (Mesoscale Discovery), as per the manufacturer's instruction.

Statistical methods. Data were summarised using descriptive statistics using number of patients, mean, median, s.d. and range for continuous variables and using frequency and percentages for discrete variables.

Descriptive statistics for PK parameters were calculated using $\mathrm{R}$ (version 2.11.1, The $\mathrm{R}$ Foundation for Statistical Computing, Vienna, Austria).

\section{RESULTS}

Patients. Between September 2008 and September 2010, 41 patients were enrolled at three sites; 37 patients had a solid tumour and four patients had multiple myeloma. Twenty-three subjects (56\%) were female, and 18 (44\%) were male, with a mean age of 60.7 years (range, 18-87 years). Most subjects were white (38 subjects, 93\%). Twenty-four subjects received ficlatuzumab as monotherapy $(2 \mathrm{mg}$ $\left.\mathrm{kg}^{-1}, n=3 ; 5 \mathrm{mg} \mathrm{kg}^{-1}, n=3 ; 10 \mathrm{mg} \mathrm{kg}^{-1}, n=3 ; 20 \mathrm{mg} \mathrm{kg}^{-1}, n=15\right)$, and 13 subjects received the ficlatuzumab/erlotinib combination. Only one of the patients on the combination therapy had received a prior EGFR inhibitor (erlotinib).

Tumour types varied widely, with the most common (defined as being diagnosed in two or more patients) being ovarian ( $n=4)$, GBM $(n=3)$ and mesothelioma $(n=3)$. Two patients with lung cancer participated (non-small cell not otherwise specified and squamous cell), both of whom were enrolled in the erlotinib combination cohort. All patients had prior surgery, radiotherapy and/or systemic treatment. Demographic and baseline disease characteristics for all solid tumour cohorts are summarised in Table 1.

Determination of the RP2D of ficlatuzumab. No DLTs occurred in any dose-escalation cohort or the safety expansion cohort. Based on the absence of DLTs, the highest administered dose, ficlatuzumab $20 \mathrm{mg} \mathrm{kg}^{-1}$ once every 2 weeks (q2w), was determined to be the RP2D. The ficlatuzumab $20 \mathrm{mg} \mathrm{kg}^{-1}$ dose-escalation cohort $(n=4)$ and the safety expansion cohort $(n=11)$ were combined for all subsequent analyses of ficlatuzumab at the RP2D as monotherapy.

Determination of the RP2D of ficlatuzumab plus erlotinib. One patient in the combination cohort experienced a DLT (grade 3 mucositis during cycle 2), which the investigator considered to be related to both agents and which required concurrent medication and erlotinib interruption. The combination cohort was expanded to 13 patients, and the RP2D was determined to be ficlatuzumab $20 \mathrm{mg} \mathrm{kg}^{-1} \mathrm{q} 2 \mathrm{w}$ plus erlotinib $150 \mathrm{mg} \mathrm{day}^{-1}$ continuously.

Treatment exposure. In the monotherapy RP2D cohort, the median administered dose was ficlatuzumab $20 \mathrm{mg} \mathrm{kg}^{-1}$ (range, $16-21$ ), with a median duration of 8.1 weeks (range, $2-102$ ). In the erlotinib combination cohort, patients received median doses of ficlatuzumab $20.0 \mathrm{mg} \mathrm{kg}^{-1}$ and erlotinib $150 \mathrm{mg} \mathrm{day}^{-1}$; 11 of 13 combination patients had $\geqslant 90 \%$ relative dose intensity. The median treatment duration in the combination cohort was 4 weeks. Of the patients who withdrew from the study, the most common reasons were disease progression (monotherapy $\mathrm{RP} 2 \mathrm{D}, n=8$; erlotinib combination, $n=8$ ) and treatment failure (monotherapy RP2D, $n=5$; erlotinib combination, $n=3$ ). Patient disposition and treatment for all solid tumour cohorts are summarised in Supplementary Table A6.

Safety and tolerability. All 41 enrolled patients were included in the safety population. The most commonly occurring (five or more patients) all-grade treatment-emergent AEs (TEAEs) in the monotherapy solid tumour patients $(n=24)$, regardless of relationship, were peripheral oedema $(n=12)$, fatigue $(n=11)$, nausea $(n=7)$ and headache $(n=6)$, as well as dyspnoea, vomiting and hypomagnesaemia (each $n=5$ ). The majority of events were grade 1 or 2. Treatment-related AEs included two patients enrolled in the 5 and $10 \mathrm{mg} \mathrm{kg}^{-1}$ monotherapy cohorts (grade 3 diarrhoea and grade 3 fatigue, which both resolved) as well as one patient in the $20 \mathrm{mg} \mathrm{kg}^{-1}$ RPD2 cohort with grade 4 episodes of hypokalaemia followed by a subsequent serious $\mathrm{AE}$ of hyperkalaemia. The most frequent TEAEs are summarised by cohort in Table 2 .

Nine of 24 patients receiving ficlatuzumab monotherapy required treatment interruption because of an AE. Two of the nine patients had grade 3 events (pneumonia and anaemia) that were reported as serious but unlikely related to study treatment. No patient required dose reduction (Supplementary Table A7).

The most commonly occurring (four or more patients) all grade TEAEs in the erlotinib combination cohort $(n=13)$ were maculopapular rash $(n=8)$, diarrhoea $(n=6)$, and dermatitis 
Table 1. Patient demographic and baseline disease characteristics

\section{Monotherapy cohorts}

\begin{tabular}{|c|c|c|c|c|c|}
\hline Characteristic & $\begin{array}{c}2 \mathrm{mg} \mathrm{kg}^{-1} \\
(n=3)\end{array}$ & $\begin{array}{c}5 \mathrm{mg} \mathrm{kg}^{-1} \\
(n=3)\end{array}$ & $\begin{array}{c}10 \mathrm{mg} \mathrm{kg}^{-1} \\
(n=3)\end{array}$ & $\begin{array}{c}\text { RP2D } 20 \mathrm{mg} \mathrm{kg}^{-1 \mathrm{a}} \\
(n=15)\end{array}$ & $\begin{array}{l}\text { Erlotinib combination } \\
\quad \text { cohort }(n=13)\end{array}$ \\
\hline Sex, $n$ female/male & $2 / 1$ & $1 / 2$ & $1 / 2$ & $10 / 5$ & $7 / 6$ \\
\hline Median age (range), years & $64(44-84)$ & $80(58-84)$ & $71(54-72)$ & 62 (19-87) & $61(18-78)$ \\
\hline \multicolumn{6}{|l|}{ Race, $n$} \\
\hline White & 3 & 1 & 3 & 14 & 13 \\
\hline Other & 0 & 2 & 0 & 1 & 0 \\
\hline
\end{tabular}

\section{ECOG performance status, $n$}

\begin{tabular}{|l|l|l|l|r|r}
\hline 0 & 0 & 0 & 0 & 4 & 1 \\
1 & 3 & 3 & 3 & 7
\end{tabular}

\section{Prior treatment}

Surgery, radiotherapy, systemic

therapy

Disease stage, $n$

II $\quad 0$

III

IV

\begin{tabular}{|l|l|l}
\hline 3 & 3 & \\
\hline
\end{tabular}

$3 \quad 15$

13

Abbreviations: $\mathrm{ECOG}=$ Eastern Cooperative Oncology Group; RP2D = recommended phase II dose.

a The monotherapy RP2D cohort includes the $20 \mathrm{mg} \mathrm{kg}^{-1}$ dose-escalation cohort and the safety expansion cohort.

Table 2. TEAEs occurring in $\geqslant 20 \%$ of patients in the monotherapy RP2D or the erlotinib combination cohort

\begin{tabular}{|c|c|c|c|c|c|c|}
\hline & \multicolumn{5}{|c|}{ Monotherapy } & \multirow[b]{2}{*}{$\begin{array}{l}\text { Erlotinib combination } \\
\text { cohort }(n=13)\end{array}$} \\
\hline TEAE, all grades/grade $\geqslant 3, n$ & $\begin{array}{c}2 \mathrm{mg} \mathrm{kg}^{-1} \\
(n=3)\end{array}$ & $\begin{array}{c}5 \mathrm{mg} \mathrm{kg}^{-1} \\
(n=3)\end{array}$ & $\begin{array}{c}10 \mathrm{mg} \mathrm{kg}^{-1} \\
(\mathrm{n}=3)\end{array}$ & $\begin{array}{c}\text { RP2D } \\
20 \mathrm{mg} \mathrm{kg}^{-1 \mathrm{a}} \\
(n=15)\end{array}$ & $\begin{array}{l}\text { All monotherapy } \\
(n=24)\end{array}$ & \\
\hline Fatigue & $1 / 0$ & $2 / 0$ & $3 / 1$ & $5 / 0$ & $11 / 1$ & $4 / 0$ \\
\hline Peripheral oedema & $1 / 0$ & $2 / 0$ & $1 / 1$ & $8 / 1$ & $12 / 2$ & $1 / 0$ \\
\hline Nausea & $0 / 0$ & $2 / 0$ & $1 / 0$ & $4 / 0$ & $7 / 0$ & $3 / 0$ \\
\hline Diarrhoea & $1 / 0$ & $1 / 1$ & $0 / 0$ & $1 / 0$ & $3 / 1$ & $6 / 0$ \\
\hline Hypokalaemia & $1 / 0$ & $0 / 0$ & $0 / 0$ & $4 / 4$ & $4 / 4$ & $4 / 0$ \\
\hline Rash, maculopapular & $0 / 0$ & $0 / 0$ & $0 / 0$ & $0 / 0$ & $0 / 0$ & $8 / 0$ \\
\hline Vomiting & $0 / 0$ & $0 / 0$ & $0 / 0$ & $5 / 1$ & $5 / 1$ & $3 / 0$ \\
\hline Hypomagnesaemia & $1 / 0$ & $0 / 0$ & $1 / 0$ & $3 / 0$ & $5 / 0$ & $2 / 0$ \\
\hline Headache & $0 / 0$ & $1 / 0$ & $2 / 0$ & $3 / 0$ & $6 / 0$ & $1 / 0$ \\
\hline Dyspnoea & $0 / 0$ & $1 / 0$ & $1 / 0$ & $3 / 1$ & $5 / 1$ & $1 / 0$ \\
\hline Pruritus & $0 / 0$ & $1 / 0$ & $1 / 0$ & $0 / 0$ & $2 / 0$ & $3 / 0$ \\
\hline Urinary tract infection & $0 / 0$ & $0 / 0$ & $1 / 0$ & $3 / 0$ & $4 / 0$ & $1 / 1$ \\
\hline Dermatitis acneiform & $0 / 0$ & $0 / 0$ & $0 / 0$ & $0 / 0$ & $0 / 0$ & $4 / 0$ \\
\hline Dysphonia & $0 / 0$ & $0 / 0$ & $0 / 0$ & $3 / 0$ & $3 / 0$ & $0 / 0$ \\
\hline
\end{tabular}

acneiform, fatigue and hypokalaemia (each $n=4$ ). With the exception of a patient who withdrew from treatment because of a grade 3 urinary tract infection resulting in hospitalisation that was unlikely related to treatment, the most frequent events were grade 1 or 2 . One patient in this cohort experienced grade 3 mucosal inflammation that was determined to be related to both agents and required temporary interruption of erlotinib; this patient also had recurrent grade 2 mucosal inflammation that required erlotinib dose reduction. No other treatment modifications were required in the combination cohort (Supplementary Table A3). 
Six monotherapy patients died during the study or within 30 days after the last dose (one in the $2 \mathrm{mg} \mathrm{kg}^{-1}$ cohort, two in the $10 \mathrm{mg} \mathrm{kg}^{-1}$ cohort and three in the safety expansion cohort). Each of these deaths was considered a result of disease progression, with the exception of one patient in the safety expansion cohort whose death was reported to be unlikely related to study drug and related to a grade 4 comminuted intertrochanteric fracture resulting in hospitalisation, treatment discontinuation and death. In the

Table 3. Best overall response (efficacy evaluable population)

\section{Monotherapy}

\begin{tabular}{|l|c|c|c|c|c|c|}
\hline Response, $\mathbf{n}^{\mathrm{a}}$ & $\begin{array}{c}\mathbf{2} \mathbf{m g ~ k g}^{-1} \\
(\mathbf{n}=\mathbf{3})\end{array}$ & $\begin{array}{c}\mathbf{5} \mathbf{m g ~ k g}^{-1} \\
(\mathbf{n}=\mathbf{3})\end{array}$ & $\begin{array}{c}\mathbf{1 0} \mathbf{m g ~ k g}^{-1} \\
(\mathbf{n}=\mathbf{3})\end{array}$ & $\begin{array}{c}\text { RP2D 20 } \mathbf{~ g ~ k g}^{-1 b} \\
(\mathbf{n}=\mathbf{1 3})\end{array}$ & $\begin{array}{c}\text { All monotherapy } \\
(\mathbf{n}=\mathbf{2 4})\end{array}$ & $\begin{array}{c}\text { Erlotinib combination } \\
\text { cohort }(\boldsymbol{n}=\mathbf{8})\end{array}$ \\
\hline Objective response & 0 & 0 & 0 & 0 & 0 & 0 \\
\hline Stable disease & 1 & 3 & 1 & 7 & 12 & 2 \\
\hline Progressive disease & 1 & 0 & 2 & 6 & 9 & 6 \\
\hline
\end{tabular}

Abbreviation: RP2D = recommended phase $\|$ dose.

${ }^{\mathrm{a}}$ Eight patients (three monotherapy/five erlotinib combination) were withdrawn from the study before completion of cycle 4 for reasons other than progressive disease and were not evaluable for response assessment.

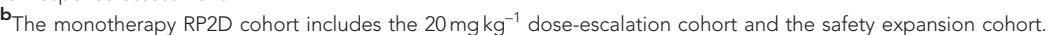

${ }^{c}$ Partial or complete responses were to be confirmed by repeat assessments performed $\geqslant 4$ weeks after the criteria for response were first met.
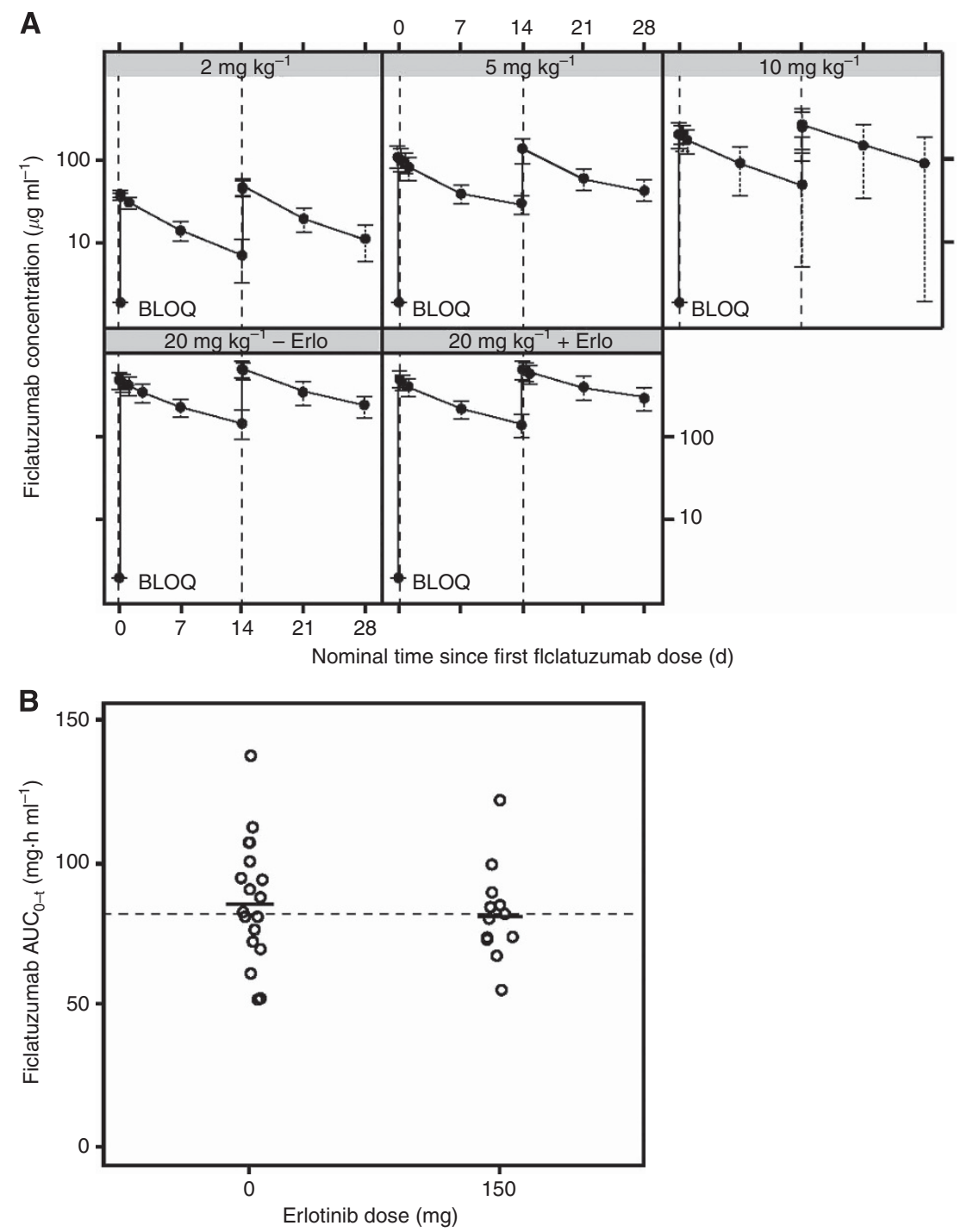

Figure 1. Ficlatuzumab exposure as a function of cycle 1 dose. (A) Ficlatuzumab concentration-time profiles by dose for cycle 1. (B) Comparison of ficlatuzumab $\mathrm{AUC}_{0 \rightarrow \tau}$ in patients administered ficlatuzumab alone vs ficlatuzumab with concurrent erlotinib treatment in cycle 1. Abbreviations: $A \cup C_{0 \rightarrow \tau}=$ area under the concentration-time curve from time zero to immediately before the next dose; Erlo=erlotinib. 
combination cohort, a rhabdomyosarcoma patient discontinued treatment and died because of respiratory distress secondary to disease progression.

Three patients discontinued the study because of an AE unlikely related to study drug; these were the two patients who died following the events of comminuted intertrochanteric fracture and respiratory distress described above and the patient in the combination cohort who discontinued owing to a urinary tract infection.

Antitumour activity. Best overall response (ficlatuzumab monotherapy or combination therapy) was SD (four cycles or 8 weeks) observed in $44 \%$ of evaluable patients. Among the evaluable ficlatuzumab monotherapy patients, 12 of 21 (57\%) had SD, including 7 of 13 (54\%) evaluable patients in the RP2D cohort. The disease control rate (DCR; $C R+P R+S D \geqslant 8$ weeks) for the RP2D cohort was 54\% (95\% confidence interval (CI): 25-81\%). Best overall response by cohort is presented in Table 3 . Stable disease of at least 16 weeks duration was observed in $14.7 \%$ (5 out of 34 ) of patients receiving either ficlatuzumab monotherapy or combination therapy.

Two monotherapy patients experienced prolonged SD $(>12$ months). One patient with a papillary thyroid tumour in the ficlatuzumab $5 \mathrm{mg} \mathrm{kg}^{-1}$ dose cohort had previous therapy of radioactive iodine and, before the study, had four cycles of doxorubicin/cisplatin before progressive disease occurred in the neck lymph nodes. On ficlatuzumab, this patient achieved SD for 54 weeks. A second patient with mixed mesodermal (Müllerian) tumour of the ovary who was enrolled in the $20 \mathrm{mg} \mathrm{kg}^{-1}$ cohort (actual dose $16.5 \mathrm{mg} \mathrm{kg}^{-1}$ ) had been treated with three prior lines of conventional therapy but still continued to demonstrate progression. This patient received an antineuropilin inhibitor for 3 months with clearly documented progression within the abdomen. On ficlatuzumab, this patient had had long-term SD and was still receiving treatment at the time of manuscript submission with maintenance of SD after $>5$ years. This patient also has the highest tumour HGF levels among those who provided tissue for analysis (Supplementary Figure A1) and moderate levels of serum HGF $\left(2.3 \mathrm{ng} \mathrm{ml}^{-1}\right)$ at C1D1 pre-dosing. The median time to progression for evaluable patients receiving ficlatuzumab monotherapy in the RP2D cohort was 3.5 months (95\% CI: 1.6 to $>36$ months).

The best overall response observed in the combination cohort was also $\mathrm{SD}$, with two of eight evaluable patients achieving SD (DCR 25\%; 95\% CI: 3.2-65.1\%), each for 3.5 months. Median time to progression for this cohort was 1.3 months (95\% CI: $0.9-3.5$ months).

Pharmacokinetics. The PK of ficlatuzumab is characterized by low clearance (CL), long terminal half-life and volume of distribution $\left(\mathrm{V}_{\mathrm{d}}\right)$ that approximates the plasma volume. The CL, half-life and $\mathrm{V}_{\mathrm{d}}$ were $166 \mathrm{ml} \mathrm{h}^{-1} \mathrm{~kg}^{-1}, 9.4$ days and $49 \mathrm{ml} \mathrm{kg}^{-1}$, respectively, in the monotherapy $\mathrm{RP} 2 \mathrm{D}$ cohort, and these results were similar in comparison with the other dose groups. Examination of individual patient concentration-time profiles across treatment cohorts suggested two-compartment PK. The maximum serum concentration and area under the serum concentration-time curve increased proportionally with dose within the range studied (Figure 1A). There was clear evidence of drug accumulation from cycle 1 to cycle 2, but accumulation to steady-state levels could not be demonstrated on the basis of only two treatment cycles. There was no evidence of any impact of concurrent erlotinib treatment on the PK of ficlatuzumab; the serum profiles and exposure parameters obtained for ficlatuzumab monotherapy and in combination with erlotinib were virtually indistinguishable from one another (Figure 1A and B and Table 4). The PK of erlotinib was broadly comparable with reported values in the literature (Lu et al, 2005).

ADA analyses. Among the 41 subjects enrolled in the study, 29 had at least one post-dose sample tested for ADA. All samples tested were negative for ADA. The median follow-up for ADA was 68 days, ranging from 27 to 607 days. Ficlatuzumab did not appear to be immunogenic at the doses tested.

Biomarker analyses. Serum HGF and c-Met were evaluated at various time points before and after ficlatuzumab administration. Bone marrow was also collected before and after ficlatuzumab administration for the multiple myeloma cohort to measure HGF, $\mathrm{c}-\mathrm{Met}$ and p-Met levels in the BM and to determine if ficlatuzumab can modulate $\mathrm{p}$-Met in these patients.

Table 4. Summary of ficlatuzumab pharmacokinetic parameters for subjects by treatment group in cycles 1 and 2

Ficlatuzumab dose

\begin{tabular}{|c|c|c|c|c|c|c|c|c|c|c|}
\hline & \multicolumn{10}{|c|}{ Ficlatuzumab dose } \\
\hline Pharmacokinetic parameter ${ }^{a}$ & $2 \mathrm{mg}$ & $N$ & $5 \mathrm{mg}$ & $N$ & $10 \mathrm{mg}$ & $N$ & $\begin{array}{c}20 \mathrm{mg} \\
\text { (monotherapy) }\end{array}$ & $N$ & $\begin{array}{c}20 \mathrm{mg} \\
(+ \text { erlotinib) }\end{array}$ & $N$ \\
\hline \multicolumn{11}{|l|}{ Cycle 1} \\
\hline$C_{\max }\left(\mu \mathrm{gml}^{-1}\right)$ & $40.63(1.55)$ & 3 & $111.3(31.60)$ & 3 & $214.0(62.75)$ & 3 & $488.3(112.3)$ & 18 & $512.8(95.20)$ & 12 \\
\hline $\mathrm{T}_{\max }(\mathrm{h})$ & $1.997(1.709)$ & 3 & $1.407(0.5405)$ & 3 & $4.717(4.071)$ & 3 & $2.714(2.736)$ & 18 & $4.888(6.822)$ & 12 \\
\hline$A \cup C_{0-\tau}\left(m g \cdot h m^{-1}\right)$ & $6.568(1.776)$ & 3 & $18.58(7.585)$ & 3 & $37.28(16.45)$ & 3 & $85.96(21.82)$ & 18 & $81.44(16.92)$ & 12 \\
\hline $\mathrm{CL}\left(\mathrm{ml} \mathrm{h}^{-1} \mathrm{~kg}^{-1}\right)$ & $0.2593(0.09535)$ & 3 & $0.2017(0.07111)$ & 3 & $0.2363(0.1151)$ & 3 & $0.1661(0.06415)$ & 18 & $0.1815(0.04376)$ & 11 \\
\hline$t_{1 / 2}(h)$ & $164.0(35.34)$ & 3 & $202.3(10.79)$ & 3 & $193.0(73.08)$ & 3 & $225.0(74.02)$ & 18 & $206.6(59.86)$ & 11 \\
\hline $\mathrm{V}_{\mathrm{d}}\left(\mathrm{ml} \mathrm{kg}^{-1}\right)$ & $58.27(6.786)$ & 3 & $59.00(22.13)$ & 3 & $57.80(15.92)$ & 3 & $49.39(10.98)$ & 18 & $51.52(9.020)$ & 11 \\
\hline \multicolumn{11}{|l|}{ Cycle 2} \\
\hline$C_{\max }\left(\mu \mathrm{g} \mathrm{ml}^{-1}\right)$ & $49.10(9.777)$ & 3 & $136.7(44.82)$ & 3 & $267.0(137.4)$ & 3 & $643.0(138.6)$ & 18 & $694.7(120.3)$ & 11 \\
\hline $\mathrm{T}_{\max }(\mathrm{h})$ & $1.520(0.7472)$ & 3 & $2.367(1.097)$ & 3 & $1.377(0.2359)$ & 3 & $1.848(1.038)$ & 18 & $4.029(2.631)$ & 11 \\
\hline$t_{1 / 2}(h)$ & $160.9(42.89)$ & 3 & $220.8(\mathrm{NC})$ & 2 & $249.9(\mathrm{NC})$ & 1 & $255.4(66.94)$ & 11 & $225.8(57.52)$ & 10 \\
\hline
\end{tabular}


Patients from the trial had higher pre-dose HGF levels at C1D1 than those measured in the serum of 36 healthy donors (samples purchased from Bioreclamation, Westbury, NY, USA) by Student's $t$-test (Figure 2A). This is consistent with the observation that serum HGF was elevated in many cancers (Christensen et al, 2005). The presence of ficlatuzumab does not interfere with HGF detection in the method used; therefore, the sum of free and ficlatuzumab-complexed HGF was measured. The pre-dose HGF level at C1D1 was used as baseline to derive fold increase in total HGF levels for each time point for each subject. The HGF fold increase over baseline was plotted as a function of time (Figure 2B). An increase in HGF levels compared with baseline was observed in all subjects tested, suggesting ficlatuzumab administration can increase total HGF levels, likely by stabilising HGF upon forming an HGF-ficlatuzumab complex and/or induction of HGF production. There was a statistically significant increase in serum total HGF at all post-dose time points, starting on C1D2 (or C1D3-4 for four multiple myeloma patients), with average fold increases of 2.0, 5.5, 8.0, 6.8, 6.2 and 12.3 at C1D2, C1D8, C2D1PRE, C2D1HR2, C2D8 and C4D8-14, respectively.
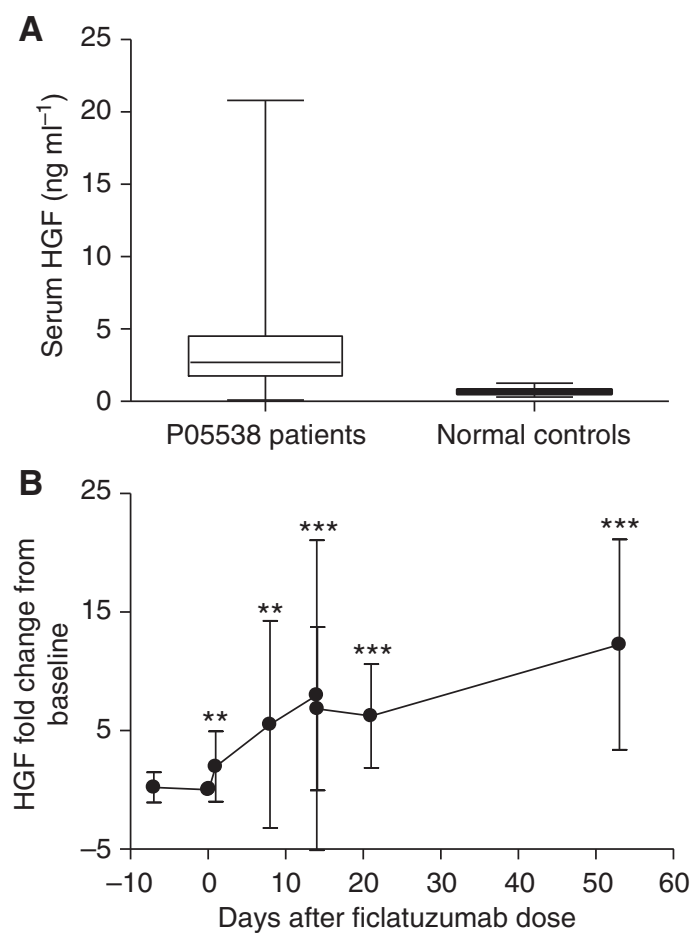

Note: ${ }^{* *} 0.01<P<0.001,{ }^{* *} P<0.001$

Figure 2. Serum HGF levels. Serum HGF levels were measured using validated ELISA assay (R\&D Systems). (A) Higher HGF levels were observed in trial cancer patients than in normal controls. Pre-dosing HGF levels for P05538 patients were derived from the average of levels at screening and C1D1 pre-dosing. Hepatocyte growth factor levels from normal controls (41 cases) were measured using the same method. Median, quartile, maximum, minimum were indicated in the box plot. On average, cancer patients in $\mathrm{P} 05538$ have 5.8-fold higher HGF than normal control ( $3.93 \mathrm{vs} 0.68 \mathrm{ng} \mathrm{m}^{-1}$ ), and the difference is statistically significant based on Student's t-test $(P<0.001)$. (B) Serum HGF levels increases after ficlatuzumab treatment. Hepatocyte growth factor fold change from baseline was derived from for each time point as follows: (HGF-HGF at C1D1-pre)/ HGF at C1D1-pre. Average fold change at each time point from all cohorts were plotted as a function of time relative to the start of ficlatuzumab treatment. Abbreviations: C1D1= cycle 1 day 1; $\mathrm{HGF}=$ hepatocyte growth factor.
Soluble c-Met (s-Met), most likely from extracellular domain shed from cell surface, was observed at high levels in all patients, with a median level of $92.4 \mathrm{ng} \mathrm{ml}^{-1}$ (ranging from 40.0 to $202.1 \mathrm{ng} \mathrm{m}^{-1}$ ) at baseline during screening. There was a modest $(13.5 \%)$ but significant $(P<0.004$, by Student's $t$-test $)$ increase in s-Met levels only after 50 days of ficlatuzumab exposure compared with baseline screening, but there was no increase observed in ficlatuzumab and erlotinib combination therapy cohort during the observation period.

Detectable HGF was observed in BM cell lysates of all four multiple myeloma patients at baseline. Ficlatuzumab treatment increased BM HGF in three of the four multiple myeloma patients. This is consistent with the increased serum HGF with ficlatuzumab treatment as previously described. There were detectable c-Met and p-Met levels in two of the four subjects at baseline. One patient experienced decreased c-Met (497-160 units, 68\% decrease) and p-Met (200-153 units, 23\% decrease) after ficlatuzumab treatment. It is not clear if this resulted from ficlatuzumab treatment or other factors, such as sample heterogeneity.

DISCUSSION

Targeting the HGF/c-Met axis as an antitumour strategy is currently being pursued through multiple approaches, including HGF-neutralising monoclonal antibodies, such as ficlatuzumab and rilotumumab, recombinant protein competitive inhibitor of HGF, antibodies to c-Met, such as ornatumumab and c-Met small molecule inhibitors, such as crizotinib (Zhang et al, 2004; Imai and Takaoka, 2006; Comoglio et al, 2008; Knudsen and Vande Woude, 2008; Eder et al, 2009).

In this study, ficlatuzumab monotherapy was well tolerated in patients with solid tumours at 2, 5 or $10 \mathrm{mg} \mathrm{kg}^{-1}$ or at the maximum administered dose of $20 \mathrm{mg} \mathrm{kg}^{-1}$. No DLTs were reported, establishing the RP2D dose for ficlatuzumab as $20 \mathrm{mg} \mathrm{kg}^{-1}$ IV once q2 $\mathrm{w}$. The most commonly observed toxicities were peripheral oedema, fatigue and nausea. Peripheral oedema, mostly grades 1-2, was also observed in trials with other HGF/c-Met targeting antibodies, such as rilotumumab and onartuzumab (Gordon et al, 2010; Spigel et al, 2011, 2012).

Pre-clinical studies (Zhang et al, 2010) and a clinical trial (Schiller et al, 2010; Mok et al, 2011) have demonstrated that targeting c-Met in combination with EGFR may result in antitumour activity. In the study reported here, ficlatuzumab at the RP2D in combination with the erlotinib dose of $150 \mathrm{mg} \mathrm{day}^{-1}$ was found to be well tolerated in patients with advanced solid tumours, with only 1 of 13 patients in the combination cohort experiencing a DLT (grade 3 mucositis).

In addition, SD ( $\geqslant 8$ weeks) was observed in $44 \%$ of evaluable patients (receiving ficlatuzumab monotherapy or combination therapy), including two patients who experienced prolonged disease control $>12$ months. The ongoing patient with $\mathrm{SD}>5$ years has also demonstrated the highest tumour HGF.

The PK profile of ficlatuzumab was characterised by low CL and long half-life, consistent with that of other monoclonal antibodies. Accumulation was observed with subsequent treatment cycles, and exposure increased in a dose-proportional manner. The long halflife of approximately 9.4 to 10.6 days at the R2PD supports an every-2-week dosing schedule, with trough levels above the half maximal inhibitory concentration in pre-clinical models. The administration of erlotinib in combination with ficlatuzumab had no detectable impact on the PK of either agent. Ficlatuzumab was not immunogenic. Pre-treatment serum HGF levels were significantly higher in study patients than in healthy volunteers (Figure 2), consistent with observations of elevated HGF in many types of cancers (Christensen et al, 2005). Increased serum HGF levels compared with baseline were observed in all patients dosed 
with ficlatuzumab, and the elevation was apparent as early as 1 day after dose and persisted through the observation period of approximately 50 days. Although increases were detectable following the lowest ficlatuzumab administered dose, the sample number was not large enough to determine a dose response. The increase was likely due to the stabilisation of HGF upon complex formation with ficlatuzumab and was not affected in the presence of erlotinib. In contrast, s-Met increase was not consistent, and a mild increase over baseline was only observed with prolonged exposure at approximately day 50. Although c-Met expression by IHC and/or fluorescence in situ hybridisation analysis was performed on archived formalin-fixed paraffin-embedded specimens, the data were not validated and therefore not reliable to present here. The increase in total HGF after ficlatuzumab administration indicates target engagement. Serum HGF increases after ficlatuzumab administration makes HGF the most robust and convenient pharmacodynamic marker for ficlatuzumab treatment. Despite the increase in total HGF, the level of ficlatuzumab $\left(\mu \mathrm{g} \mathrm{ml}^{-1}\right)$ in the serum is still higher than the serum HGF level $\left(\mathrm{ng} \mathrm{ml}^{-1}\right)$; therefore, most of the HGF is likely to be in the form of HGF-ficlatuzumab complex. These observations are consistent with those observed for other anti-HGF antibodies, such as rilotumumab (Gordon et al, 2010) and TAK701 (Jones et al, 2010), suggesting that increased HGF levels after anti-HGF antibody treatment is likely a class effect.

Specific antibodies for HGF and c-Met have demonstrated promising clinical activity in randomised phase II trials in c-Met biomarker selected patients (Spigel et al, 2011; Oliner et al, 2012) and are currently being evaluated in phase III trials in NSCLC and metastatic gastric or oesophagogastric junction cancer. Ficlatuzumab is a potent HGF antibody with demonstrated antitumour activity in pre-clinical models and preliminary clinical activity.

The findings from this study have supported the continued clinical development of ficlatuzumab, a member of a new class of anticancer agents. A randomised phase II study in first-line NSCLC patients treated with gefitinib with or without ficlatuzumab is ongoing (Mok et al, 2012). The phase II dose for that study was based on this study presented here, as well as on pre-clinical data obtained for ficlatuzumab.

\section{ACKNOWLEDGEMENTS}

We wish to acknowledge all the participating patients and their families, as well as the network of investigators, research nurses, study coordinators and operations staff. Editorial/medical writing support was provided by Marina Paul, PhD, of SciFluent, Raffy Dakessian, $\mathrm{PhD}$, of Scientific Connexions and Maria Cincotta from AVEO Oncology and was funded by AVEO Oncology. This study was supported by AVEO Pharmaceuticals, Inc.

\section{CONFLICT OF INTEREST}

Other than research support paid to the institutions, the authors declare the following conflicts: GJW is on the speaker's bureau for Genentech, Pfizer, Celgene and Eli Lilly, and has received honoraria from Quintiles and Medscape; $\mathrm{CCH}$ has been on the speaker's bureau and advisory boards for Celgene, and AT has consulting and/or advisory agreements with Astellas. Employment conflicts are reported by the following authors: JJ and FCP are current employees of AVEO and, at the time the research was being performed, $\mathrm{MH}$ and MMC were employees of AVEO and RI was an employee of Schering Plough. In addition, MMC is a stock holder for AVEO. The remaining authors declare no conflict of interest.

\section{REFERENCES}

Bean J, Brennan C, Shih JY, Riely G, Viale A, Wang L, Chitale D, Motoi N, Szoke J, Broderick S, Balak M, Chang WC, Yu CJ, Gazdar A, Pass H, Rusch V, Gerald W, Huang SF, Yang PC, Miller V, Ladanyi M, Yang CH, Pao W (2007) MET amplification occurs with or without T790M mutations in EGFR mutant lung tumors with acquired resistance to gefitinib or erlotinib. Proc Natl Acad Sci USA 26: 20932-20937.

Betsunoh H, Mukai S, Akiyama Y, Fukushima T, Minamiguchi N, Hasui Y, Osada Y, Kataoka H (2007) Clinical relevance of hepsin and hepatocyte growth factor activator inhibitor type 2 expression in renal cell carcinoma. Cancer Sci 98: 491-498.

Birchmeier C, Birchmeier W, Gherardi E, Vande Woude GF (2003) Met, metastasis, motility and more. Nat Rev Mol Cell Biol 4: 915-925.

Bottaro DP, Rubin JS, Faletto DL, Am Chan, Kmiecik TE, Vande Woude GF, Aaronson SA (1991) Identification of the hepatocyte growth factor receptor as the c-met proto-oncogene product. Science 251: 802-804.

Christensen JG, Burrows J, Salgia R (2005) c-Met as a target for human cancer and characterization of inhibitors for therapeutic intervention. Cancer Lett 225: $1-26$

Comoglio PM, Giordano S, Trusolino L (2008) Drug development of MET inhibitors: targeting oncogene addiction and expedience. Natl Rev Drug Discov 7: 504-516.

Drebber U, Baldus SE, Nolden B, Grass G, Bollschweiler E, Dienes HP, Hölscher AH, Mönig SP (2008) The overexpression of c-met as a prognostic indicator for gastric carcinoma compared to p53 and p21 nuclear accumulation. Oncol Rep 19: 1477-1483.

Durie BG, Harousseau JL, Miguel JS, Bladé J, Barlogie B, Anderson K, Gertz M, Dimopoulos M, Westin J, Sonneveld P, Ludwig H, Gahrton G, Beksac M, Crowley J, Belch A, Boccadaro M, Cavo M, Turesson I, Joshua D, Vesole D, Kyle R, Alexanian R, Tricot G, Attal M, Merlini G, Powles R, Richardson P, Shimizu K, Tosi P, Morgan G, Rajkumar SV. International Myeloma Working Group (2006) International uniform response criteria for multiple myeloma. Leukemia 20: 1467-1473.

Eder JP, Vande Woude GF, Boerner SA, LoRusso PM (2009) Novel therapeutic inhibitors of the c-Met signaling pathway in cancer. Clin Cancer Res 15: 2207-2214.

Engelman JA, Zejnullahu K, Mitsudomi T, Song Y, Hyland C, Park JO, Lindeman N, Gale CM, Zhao X, Christensen J, Kosaka T, Holmes AJ, Rogers AM, Cappuzzo F, Mok T, Lee C, Johnson BE, Cantley LC, Jänne PA (2007) MET amplification leads to gefitinib resistance in lung cancer by activating ERBB3 signaling. Science 316: 1039-1043.

Gherardi E, Birchmeier W, Birchmeier C, Vande Woude G (2012) Targeting MET in cancer: rationale and progress. Nat Rev Cancer 24: 89-103.

Gordon MS, Sweeney CS, Mendelson DS, Eckhardt SG, Anderson A, Beaupre DM, Branstetter D, Burgess TL, Coxon A, Deng H, Kaplan-Lefko P, Leitch IM, Oliner KS, Yan L, Zhu M, Gore L (2010) Safety, pharmacokinetics, and pharmacodynamics of AMG 102, a fully human hepatocyte growth factor-neutralizing monoclonal antibody, in a first-in-human study of patients with advanced solid tumors. Clin Cancer Res 16: 699-710.

Guo A, Villen J, Kornhauser J, Lee KA, Stokes MP, Rikova K, Possemato A, Nardone J, Innocenti G, Wetzel R, Wang Y, MacNeill J, Mitchell J, Gygi SP, Rush J, Polakiewicz RD, Comb MJ (2008) Signaling networks assembled by oncogenic EGFR and c-Met. Proc Natl Acad Sci USA 105: 692-697.

Imai K, Takaoka A (2006) Comparing antibody and small-molecule therapies for cancer. Natl Rev Cancer 6: 714-727.

Jones SF, Cohen RB, Bendell JC, Denlinger CS, Harvey RD, Parasuraman S, Chi X, Scholz C, Wyant T, Kauh J (2010) Safety, tolerability, and pharmacokinetics of TAK-701, a humanized anti-hepatocyte growth factor (HGF) monoclonal antibody, in patients with advanced nonhematologic malignancies: first-in-human phase I dose-escalation study. J Clin Oncol 28: abstract 3081.

Knudsen BS, Vande Woude G (2008) Showering c-MET-dependent cancers with drugs. Curr Opin Genet Dev 18: 87-96.

Lu J, Eppler S, Lum B, Hamilton M, Rakhit A, Gaudreault J (2005) A population pharmacokinetic (PK) model for erlotinib (E), a small molecule inhibitor of the epidermal growth factor receptor (EGFR). J Clin Oncol 23: abstract 2032.

Meetze K, Connolly K, Boudrow A, Tissire H, Karp R, Gyuris J, Han M (2009c) Preclinical efficacy and pharmacodynamics of SCH 900105 (AV-299), an anti-HGF antibody. AACR Meeting Abstracts (abstract 1246). 
Meetze KA, Boudrow A, Connolly K, Huang R, Rideout III W, Gyuris J, Han M (2009b) Anti-tumor activity of SCH 900105 (AV299), an antiHGF antibody, in non-small cell lung cancer models. Mol Cancer Ther 8(Suppl 12): abstract C173.

Meetze KA, Connolly K, Boudrow A, Venkataraman S, Medicherla S, Gyuris J, Han M (2009a) Preclinical efficacy and pharmacodynamics of SCH 900105 (AV-299) an anti-HGF antibody in an intracranial glioblastoma model. Mol Cancer Ther 8(Suppl 12): abstract C181.

Mok T, Tan E, Park K, Jac J, Han M, Payumo FC, Credi M, McKee K, Cotreau MM, Bhargava P, Slichenmyer W (2011) Randomized phase II study of ficlatuzumab (formerly AV-299) and anti-hepatocyte growth factor (HGF) monoclonal antibody (MAb) in combination with gefitinib (G) in Asian patients (pts) with NSCLC. J Clin Oncol 29: abstract TPS213.

Mok TSK, Park K, Geater SL, Agarwal S, Han M, Credi M, McKee K, Kuriyama N, Slichenmyer W, Tan EH (2012) A randomized phase (Ph) 2 study with exploratory biomarker analysis of ficlatuzumab (F) a humanized hepatocyte growth factor (HGF) inhibitory monoclonal antibody (MAb) in combination with gefitinib $(\mathrm{G})$ versus gefitinib alone in Asian patients with lung adenocarcinoma (LA). ESMO Annual Meeting. 28 September -2 October 2012; Vienna, Austria. abstract 1198.

Oliner K, Tang R, Anderson A, Lan Y, Iveson T, Donehower R, Jiang Y, Dubey S, Loh E (2012) Evaluation of Met-pathway biomarkers in a phase 2 study of rilotumumab plus epirubicin, cisplatin, and capecitabine in gastric/esophagogastric junction cancer. Ann Oncol 23(Suppl 4): iv8 (abstract O-0011).

Patnaik A, Weiss GJ, Papadopoulos K, Tibes R, Tolcher AW, Payumo FC, Cotreau MM, Jac J, Isaacs R, Ramanathan RK (2010) Phase 1 study of $\mathrm{SCH} 900105$, an anti-hepatocyte growth factor monoclonal antibody, as a single agent and in combination with erlotinib in patients with advanced solid tumors. J Clin Oncol 28: abstract 2525.

Ponzo MG, Lesurf R, Petkiewicz S, O’Malley FP, Pinnaduwage D, Andrulis IL, Bull SB, Chughtai N, Zuo D, Souleimanova M, Germain D, Omeroglu A, Cardiff RD, Hallett M, Park M (2009) Met induces mammary tumors with diverse histologies and is associated with poor outcome and human basal breast cancer. Proc Natl Acad Sci USA 106: 12903-12908.

Pour L, Svachova H, Adam Z, Mikulkova Z, Buresova L, Kovarova L, Buchler T, Penka M, Vorlicek J, Hajek R (2010) Pretreatment hepatocyte growth factor and thrombospondin-1 levels predict response to high-dose chemotherapy for multiple myeloma. Neoplasma 57: 29-34.

Sasaki H, Okuda K, Kawano O, Yukiue H, Yano M, Fujii Y (2008) Fibroblast growth factor receptor 4 mutation and polymorphism in Japanese lung cancer. Oncol Rep 20: 1125-1130.

Schiller JH, Akerley WL, Brugger W, Ferrari D, Garmey EG, Gerber DE, Orlov SV, Ramlau R, Von Pawel J, Sequist LV (2010) Results from ARQ 197-209: a global randomized placebo-controlled phase II clinical trial of erlotinib plus ARQ 197 versus erlotinib plus placebo in previously treated EGFR inhibitor-naive patients with locally advanced or metastatic nonsmall cell lung cancer (NSCLC). J Clin Oncol 28: abstract LBA7502.

Seiwert TY, Jagadeeswaran R, Faoro L, Janamanchi V, Nallasura V, El Dinali M, Yala S, Kanteti R, Cohen EE, Lingen MW, Martin L, Krishnaswamy S, Klein-Szanto A, Christensen JG, Vokes EE, Salgia R (2009) The MET receptor tyrosine kinase is a potential novel therapeutic target for head and neck squamous cell carcinoma. Cancer Res 69: 3021-3031.
Spigel DR, Edelman MJ, Mok T, O’Byrne KJ, Paz-Ares L, Yu W, Rittweger K, Thurm H. MetLung Phase III Study Group (2012) The MetLUNG study: a randomized, double-blind, phase III study of onartuzumab (MetMAb) plus erlotinib versus placebo plus erlotinib in patients with advanced, MET-positive non-small cell lung cancer (NSCLC). J Clin Oncol 30(Suppl): abstract TPS7616.

Spigel DR, Ervin TJ, Ramlau R, Daniel DB, Goldschmidt JH, Blumenschein GR, Krzakowski MJ, Robinet G, Clement-Duchene C, Barlesi F, Govindan R, Patel T, Orlov SV, Wertheim MS, Zha J, Pandita A, Yu W, Yauch RL, Patel PH, Peterson AC (2011) Final efficacy results from OAM4558g, a randomized phase II study evaluating MetMAb or placebo in combination with erlotinib in advanced NSCLC. J Clin Oncol 29(Suppl): abstract 7505 .

Storer BE (1989) Design and analysis of phase I clinical trials. Biometrics 45: 925-937.

Tan E, Park K, Lim WT, Ahn MJ, NG QS, Ahn JS, Tan DS, Sun J, Jac J, Han M, Payumo FC, Credi M, McKee K, Cotreau MM, Bhargava P, Slichenmyer W (2011) Phase Ib study of ficlatuzumab (formerly AV-299), an anti-hepatocyte growth factor monoclonal antibody in combination with gefitinib in Asian patients with NSCLC. J Clin Oncol 29: abstract 7571.

Tang Z, Du R, Jiang S, Wu C, Barkauskas DS, Richey J, Molter J, Lam M, Flask C, Gerson S, Dowlati A, Liu L, Lee Z, Halmos B, Wang Y, Kern JA, Ma PC (2008) Dual MET-EGFR combinatorial inhibition against T790M-EGFR-mediated erlotinib-resistant lung cancer. Br J Cancer 99: 911-922.

Trusolino L, Comoglio PM (2002) Scatter-factor and semaphorin receptors: cell signalling for invasive growth. Nat Rev Cancer 2: 289-300.

Weidner KM, Sachs M, Birchmeier W (1993) The Met receptor tyrosine kinase transduces motility, proliferation, and morphogenic signals of scatter factor/hepatocyte growth factor in epithelial cells. J Cell Biol 121: $145-154$.

Xu H, Stabile LP, Gubish CT, Gooding WE, Grandis JR, Siegfried JM (2011) Dual blockade of EGFR and c-Met abrogates redundant signaling and proliferation in head and neck carcinoma cells. Clin Cancer Res 17: 4425-4438.

Yap TA, Sandhu SK, Alam SM, de Bono JS (2011) HGF/c-MET targeted therapeutics: novel strategies for cancer medicine. Curr Drug Targets 12: 2045-2058.

Zhang YW, Graveel C, Shinomiya N, Vande Woude GF (2004) Met decoys: will cancer take the bait? Cancer Cell 6: 5-6.

Zhang YW, Staal B, Essenburg C, Su Y, Kang L, West R, Kaufman D, Dekoning T, Eagleson B, Buchanan SG, Vande Woude GF (2010) MET kinase inhibitor SGX523 synergizes with epidermal growth factor receptor inhibitor erlotinib in a hepatocyte growth factor-dependent fashion to suppress carcinoma growth. Cancer Res 70: 6880-6890.

This work is published under the standard license to publish agreement. After 12 months the work will become freely available and the license terms will switch to a Creative Commons AttributionNonCommercial-Share Alike 3.0 Unported License.

Supplementary Information accompanies this paper on British Journal of Cancer website (http://www.nature.com/bjc) 